\title{
Modeling of Alkynes: Synthesis and Theoretical Properties
}

\author{
Renato Rosseto $^{\mathrm{a}}$, José Celso Torres ${ }^{\mathrm{a}}$, Jordan Del Nero ${ }^{\mathrm{b}}$ * \\ ${ }^{\mathrm{a}}$ Instituto de Química, UNICAMP, \\ 13083-970 Campinas - SP, Brazil \\ ${ }^{\mathrm{b}}$ Departamento de Física, Universidade Federal do Pará, \\ 66075-110 Belém - PA, Brazil
}

Received: October 18, 2002; Revised: March 11, 2003

\begin{abstract}
In this paper we present the synthesis and simulation of alkynes derivatives. Semiempirical calculations were carried out for the ground and first excited states, including the spectroscopic properties of the absorption and emission (fluorescence and phosphorescence) spectra by INDO/S-CI and DNdM-INDO/S-CI methods with geometries fully optimized by PM3/CI. The fact that the theoretical spectra are in accord with the experimental absorption spectra gives us a new possible approach on how structure modifications could affect the non-linear optical properties of alkynes.
\end{abstract}

Keywords: alkynes, synthesis,semiempirical/ci methods, theoretical absorption and emission spectra, experimental absorption spectra

\section{Introduction}

Alkynes have been identified as a promising way to prepare novel molecular, polymer carbon allotropes and carbon-rich nanoarchitecture with unusual structural, electronic and optical properties ${ }^{1-4}$.

The use of the carbon-carbon triple bond as a linking unit between aromatic rings allows access to relatively rigid and simple scaffoldings that can be further elaborated by incorporating a wide range of pendant functionalities on the aromatic rings, which can promote electronic modifications and induced electronic delocalization in the compound ${ }^{4}$.

Juxtaposition of the alkyne entity and substituents appears to be interesting in several aspects: (a) two or more metal centers could be held in the same molecule ${ }^{5,6}$ for cooperative effect in catalysis; (b) metal organic polymers could be derived from organometallic complexes containing these ligands $^{7}$; (c) bridged dinuclear complexes could serve as models for the investigation of metal-metal interactions ${ }^{8}$ or the complexes may serve as nonlinear optical materials ${ }^{9}$.

Our objective in this work is to understand, by theoretical and experimental methods, the changes in the electronic properties of aromatic alkynes (electronically symmetric or asymmetric) containing different substituents on the benzene rings in para position. Diphenylacetylene (I) was taken as the reference and the other alkynes studied were grouped according to the nature of the substituent on the aromatic rings: electron donating groups (II and V), elec-

*e-mail: jordan@ufpa.br

Trabalho apresentado no $1^{\circ}$ Congresso da Sociedade Brasileira em Materiais, Rio de Janeiro, Julho de 2002. tron acceptor group (III), electron donor and acceptor group (IV). $\mathrm{C}_{6} \mathrm{H}_{4} \mathrm{~N}$ (pyridil) was used in place of the phenyl rings in alkynes VI and VII, and 1,3-diphenylbutadiyne (VIII) was studied to evaluate the extension of conjugated chain.

\section{Methodology}

All reactions were carried out under dry argon using standard Schlenk techniques. Solvents (diethylamine and triethylamine) were dried and distilled prior to use. Diphenylacetylene, phenylacetylene, 4-iodoaniline, 1-iodo4-nitrobenzene, 4-iodoanisole, and 4-bromopyridine hydrochloride were purchased from Aldrich Chemical Co send were used without further purification, and bis(triphenylphosphine)palladium(II) dichloride $\left[\mathrm{PdCl}_{2}\left(\mathrm{PPh}_{3}\right)_{2}\right]$ and cuprous iodide $(\mathrm{CuI})$ were purchased from Strem Chemical, Inc.

$\mathrm{UV}-\mathrm{V}$ is spectra were obtained from $\mathrm{CH}_{2} \mathrm{Cl}_{2}$ and hexane solutions, in a $1 \mathrm{~cm}$ path length quartz cuvette, on a HP8452 spectrometer. Infrared spectra were recorded using $\mathrm{NaCl}$ cell in nujol on a Bomem MB-Series FT-IR spectrometer.

All compounds (I-VIII) were prepared and characterized as previously described ${ }^{10-13}$ and the following is a typical example:

Alkyne II (para-aminodiphenylacetylene). To a mixture of 4-iodoaniline $(0.97 \mathrm{~g}, 5 \mathrm{mmol})$ and phenylacetylene $(0.65 \mathrm{ml}, 6 \mathrm{mmol})$ was added $\left[\mathrm{PdCl}_{2}\left(\mathrm{PPh}_{3}\right)_{2}\right](170 \mathrm{mg}$, $5 \% \mathrm{~mol})$ and $\mathrm{CuI}(47 \mathrm{mg}, 5 \% \mathrm{~mol})$ in $30 \mathrm{ml}$ a deaerated solution of triethylamine. The reaction mixture was stirred at room 
temperature for $6 \mathrm{~h}$ under $A r$ and the solvent was then removed under reduced pressure. The residue was purified by chromatography on silica using hexane: $\mathrm{CH}_{2} \mathrm{Cl}_{2}$ (4:1) as eluent. The compound was obtained as white needles, yield: $70 \%$.

For each of the structures of Table 1, the geometry was completely optimized using the PM3/CI ${ }^{14}$ (Parametric Method 3 with configuration interaction). All the PM3/CI calculations were carried out with the MOPAC $\operatorname{program}^{15}$. After the determination of the optimized geometry, the absorption spectrum of each molecule was simulated by the INDO/S-CI (Intermediate Neglect of Differential Overlap/ Spectroscopic - Configuration Interaction) ${ }^{16-19}$, with parameters chosen to give the best description of the UV-NISVisible optical transitions ${ }^{20-23}$ and approximately 250 configurations were investigated for each molecule, including singlet and doublet states. In order to obtain the fluorescence and phosphorescence spectra, the ZINDO package was modified considering the geometry of the first excited states (singlet and triplet) in the description of the emission. This approach is referred herein as DNdM-INDO/S-CI

Table 1. Schematic structures of the alkynes investigated in this work.

\begin{tabular}{|c|c|c|c|}
\hline \multicolumn{4}{|c|}{ Alkynes } \\
\hline Nickname & $\mathbf{R}_{1}$ & $\mathbf{R}_{2}$ & Molecule \\
\hline I & $\mathrm{H}$ & $\mathrm{H}$ & \\
\hline II & $\mathrm{H}$ & $15 \mathrm{~N}^{\prime}$ & \\
\hline III & $15 \mathrm{~N}^{\mathrm{O}_{17}^{16}}$ & $18 \mathrm{~N}_{\mathrm{O}_{20}}^{\mathrm{O}^{19}}$ & 8 \\
\hline IV & ${ }_{19}^{18} \mathrm{O}^{\mathrm{O}}$ & $\mathrm{O}-\mathrm{CH}_{3}$ & ${ }_{4}^{5}$ \\
\hline V & $\mathrm{O}-\mathrm{CH}_{3}$ & $\mathrm{O}-\mathrm{CH}_{3}$ & I \\
\hline VI & $\mathrm{H}$ & $(12=\mathrm{N})$ & $\mathbf{R}_{1}$ \\
\hline VII & $(3=N)$ & $(12=\mathrm{N})$ & \\
\hline VIII & $\underbrace{6-1}_{4}$ & $-7 \equiv 8-$ & $\sqrt{-11^{16-1}}$ \\
\hline
\end{tabular}

calculation, and we have taken account from the first 10-UMOs (Unoccupied Molecular Orbitals) to the last 10-OMOs (Occupied Molecular Orbitals) and adopted the Mattaga-Nishimoto $\gamma^{\prime}$ s.

\section{Results and Discussion}

The UV-visible spectra of compounds I-VIII obtain in $\mathrm{CH}_{2} \mathrm{Cl}_{2}$ (Fig. 1) and hexane (Fig. 2) were very similar. In all cases absorption bands $\left(\varepsilon \cong 2.10^{4} \mathrm{l} / \mathrm{mol} . \mathrm{cm}\right)$ were observed in the 250-400 $\mathrm{nm}$ range.

Considering alkyne I as the reference, a red shift of this band was observed in the spectra of II, III, IV and V, which was associated to the increasing electronic delocalization in the compound (see discussion below). In II and V (electrondonor groups) the shift was smaller than III (two groups $\mathrm{NO}_{2}$, electron-withdrawing). The biggest shift was observed for $\mathrm{V}$ due to an increase in the $\pi$-delocalization between two different substituents $\left(\mathrm{NO}_{2}\right.$ and $\left.\mathrm{OCH}_{3}\right)$ in backbone of alkyne.

The use of a moiety $\mathrm{C}_{5} \mathrm{H}_{4} \mathrm{~N}$ in place of a $\mathrm{C}_{6} \mathrm{H}_{5}$ group, VI, did not lead to significant changes in the UV-vis spectrum when compared with I, thus indicating that the pyridil group does not have any influence in the alkyne electronic delocalization. The largest spectroscopical changes were observed for VII (which contains two pyridil groups) and VIII (containing an extended chain).

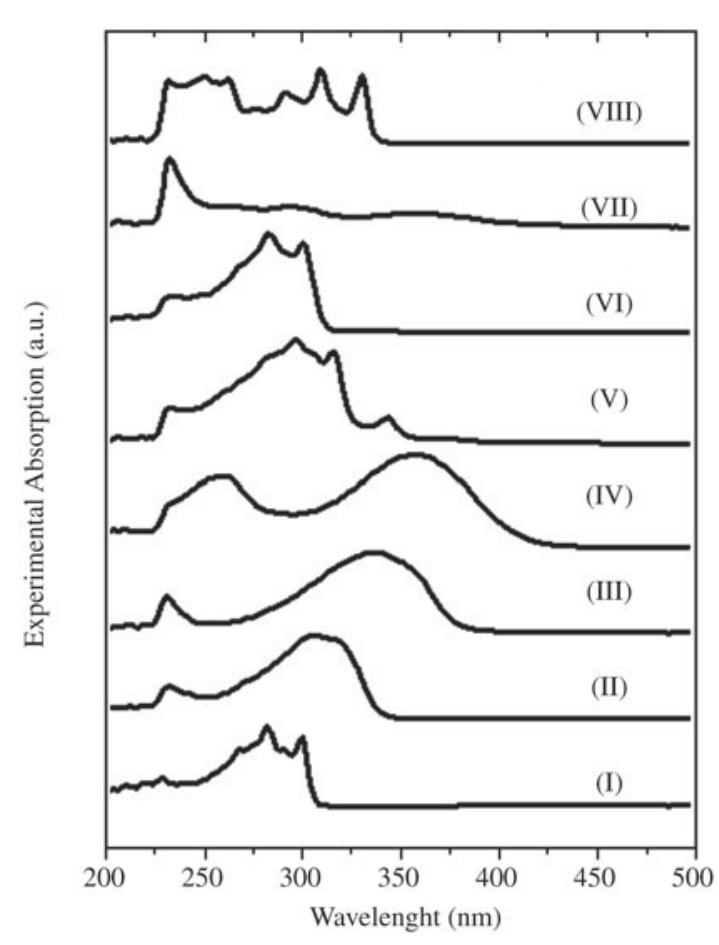

Figure 1. Experimental UV-vis absorption spectra of alkynes I-VIII (Table 1) in $\mathrm{CH}_{2} \mathrm{Cl}_{2}$ (see methodology). 


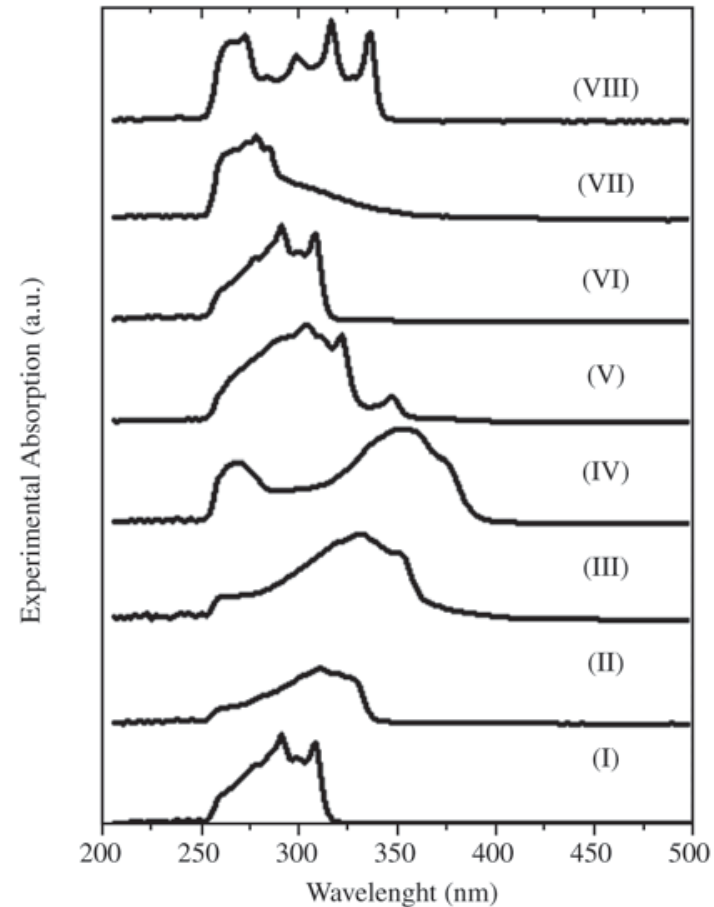

Figure 2. Experimental UV-vis absorption spectra of alkynes I-VIII (Table 1) in hexane (see methodology).

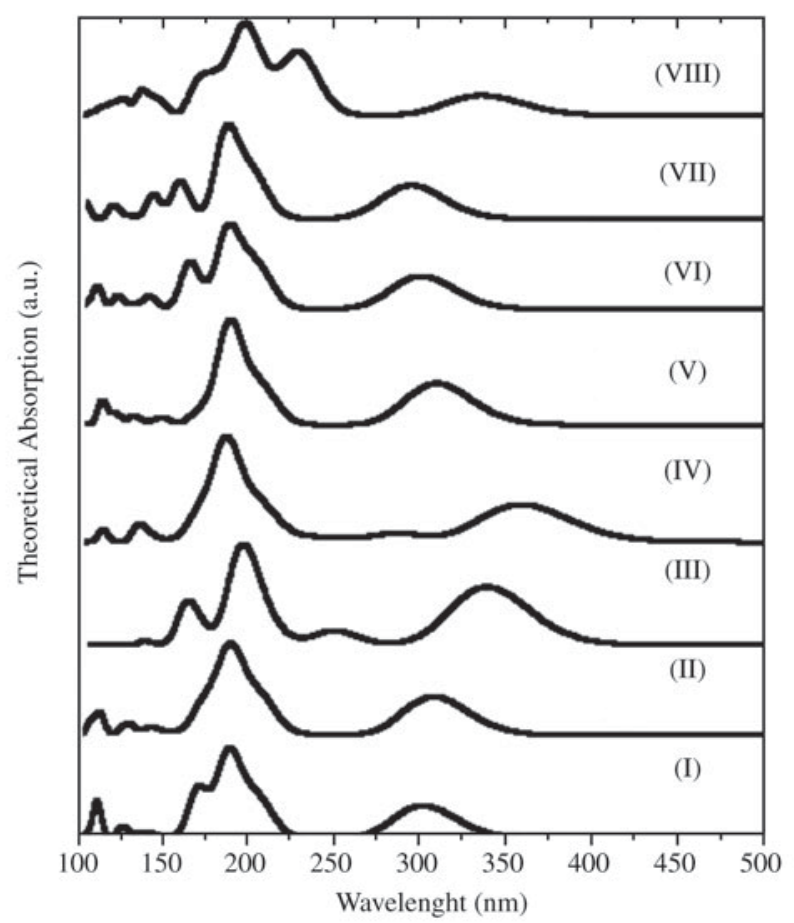

Figure 3. Theoretical UV-vis absorption spectra of alkynes I-VIII (Table 1) calculated for optimized geometries by INDO/S-CI by PM3 method.

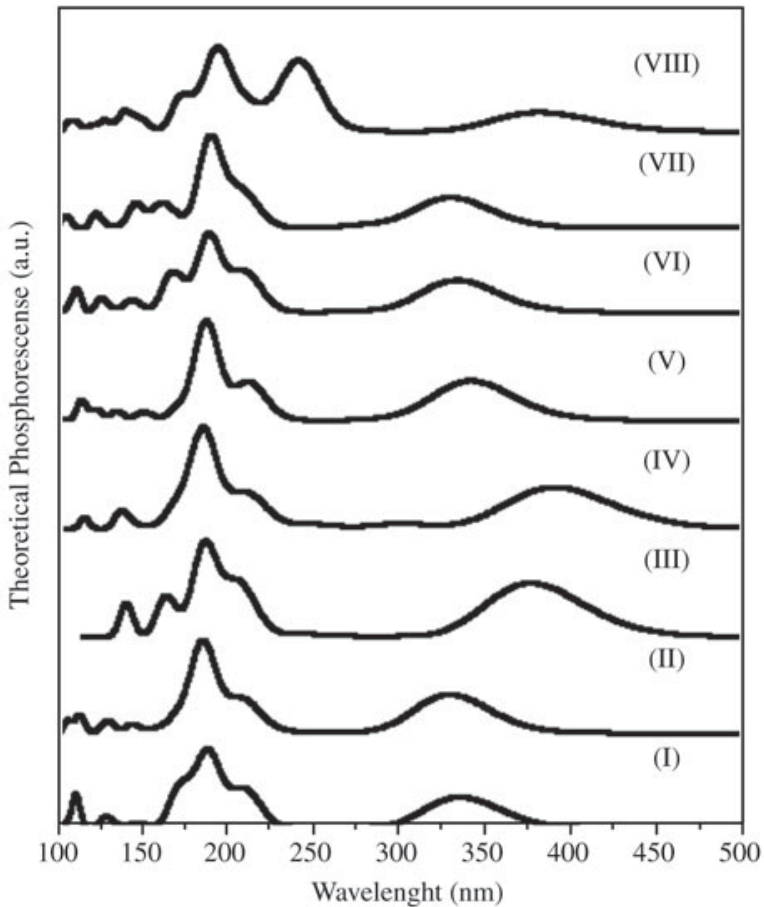

Figure 4. Theoretical UV-vis spectra of molecules I to VIII (Table 1) calculated for optimized geometries by DNdM-INDO/S-CI (fluorescence spectra) by PM3/CI method.

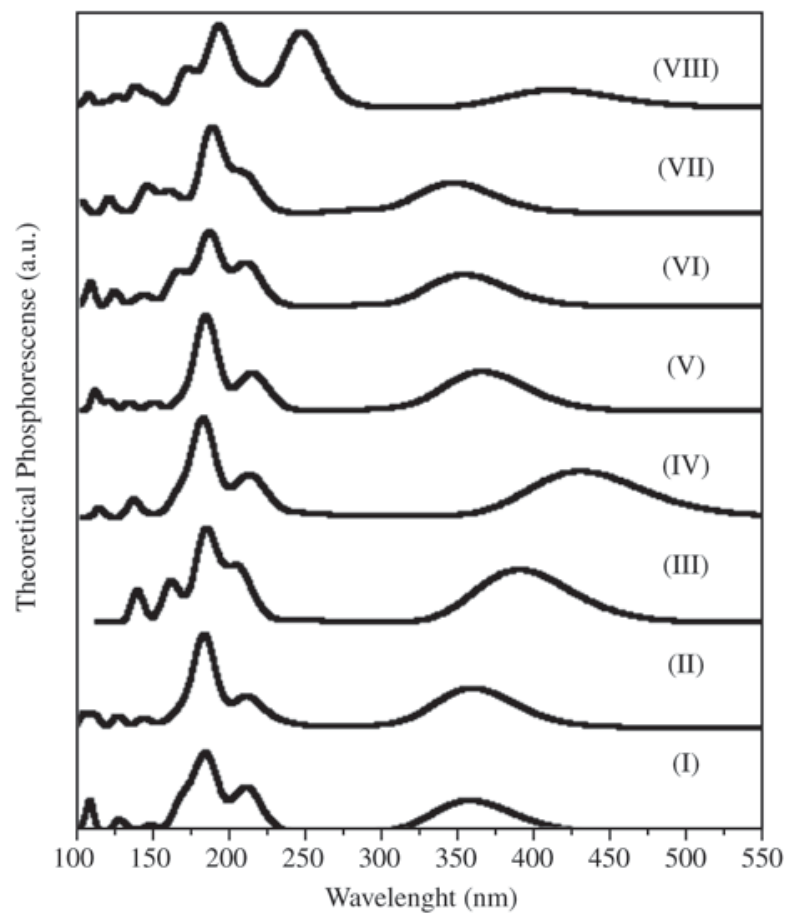

Figure 5. Theoretical UV-vis spectra of molecules I to VIII (Table 1) calculated for optimized geometries by DNdM-INDO/S-CI (phosphorescence spectra) by PM3/CI method. 
Table 2. Principal electronic UV-NIS-Vis absorption transitions as determined from INDO/S-CI calculations based on optimized groundstate geometry by PM3 for molecules I to VIII. (1/nm and o.s. represent the wavelength and the oscillator strength of the transition, respectively).

\begin{tabular}{|c|c|c|c|}
\hline Molecule & $\mathrm{nm}$ & o.s. & Absorption \\
\hline \multirow[t]{5}{*}{ (I) } & 298.9 & 0.7991 & $0.64 \mid \mathrm{H} \rightarrow \mathrm{L}>$ \\
\hline & 203.5 & 0.9141 & $0.48|\mathrm{H} \rightarrow \mathrm{L}+1>0.44| \mathrm{H}-1 \rightarrow \mathrm{L}>$ \\
\hline & 186.7 & 2.0547 & $0.32|\mathrm{H} \rightarrow \mathrm{L}+5>0.36| \mathrm{H}-1 \rightarrow \mathrm{L}+1>-0.36 \mid \mathrm{H}-2 \rightarrow \mathrm{L}+2>$ \\
\hline & 169.6 & 0.3868 & $-0.40|\mathrm{H} \rightarrow \mathrm{L}+5>-0.41| \mathrm{H}-5 \rightarrow \mathrm{L}>$ \\
\hline & 167.6 & 0.7997 & $-0.47|\mathrm{H}-2 \rightarrow \mathrm{L}+3>0.44| \mathrm{H}-4 \rightarrow \mathrm{L}+2>$ \\
\hline \multirow[t]{6}{*}{ (II) } & 305.4 & 0.9129 & $-0.65 \mid \mathrm{H} \rightarrow \mathrm{L}>$ \\
\hline & 204.6 & 0.7969 & $0.36|\mathrm{H} \rightarrow \mathrm{L}+1>0.40| \mathrm{H}-4 \mathrm{vL}>$ \\
\hline & 188.4 & 1.6040 & $0.32|\mathrm{H}-2 \rightarrow \mathrm{L}+2>-0.44| \mathrm{H}-4 \rightarrow \mathrm{L}+1>$ \\
\hline & 180.0 & 0.3721 & $0.47|\mathrm{H}-1 \rightarrow \mathrm{L}+2>0.32| \mathrm{H}-2 \rightarrow \mathrm{L}>$ \\
\hline & 175.5 & 0.4342 & $0.35 \mid \mathrm{H}-5 \rightarrow \mathrm{L}>$ \\
\hline & 168.9 & 0.2639 & $0.50 \mid \mathrm{H}-4 \rightarrow \mathrm{L}+3>$ \\
\hline \multirow[t]{7}{*}{ (III) } & 336.0 & 1.4146 & $0.66 \mid \mathrm{H} \rightarrow \mathrm{L}>$ \\
\hline & 247.7 & 0.3076 & $-0.66 \mid \mathrm{H} \rightarrow \mathrm{L}+2>$ \\
\hline & 213.6 & 0.2277 & $-0.35|\mathrm{H}-5 \rightarrow \mathrm{L}>-0.33| \mathrm{H}-6 \rightarrow \mathrm{L}+1>$ \\
\hline & 201.2 & 1.0577 & $-0.31|\mathrm{H} \rightarrow \mathrm{L}+3>-0.38| \mathrm{H}-1 \rightarrow \mathrm{L}>$ \\
\hline & 192.9 & 1.1113 & $0.44|\mathrm{H}-1 \rightarrow \mathrm{L}+3>-0.43| \mathrm{H}-2 \rightarrow \mathrm{L}+4>$ \\
\hline & 189.9 & 0.7338 & $0.35|\mathrm{H}-2 \rightarrow \mathrm{L}+1>-0.32| \mathrm{H}-2 \rightarrow \mathrm{L}+5>$ \\
\hline & 161.9 & 0.8008 & $0.40|\mathrm{H}-2 \rightarrow \mathrm{L}+5>0.48| \mathrm{H}-4 \rightarrow \mathrm{L}+4>$ \\
\hline \multirow[t]{6}{*}{ (IV) } & 355.8 & 0.9057 & $0.61 \mid \mathrm{H} \rightarrow \mathrm{L}>$ \\
\hline & 283.6 & 0.1874 & $0.59 \mid \mathrm{H} \rightarrow \mathrm{L}+1>$ \\
\hline & 206.2 & 0.2717 & $0.34 \mid \mathrm{H} \rightarrow \mathrm{L}+8>$ \\
\hline & 206.0 & 0.2559 & $-0.31|\mathrm{H} \rightarrow \mathrm{L}+5>0.36| \mathrm{H} \rightarrow \mathrm{L}+8>$ \\
\hline & 186.0 & 1.7897 & $0.52 \mid \mathrm{H}-1 \rightarrow \mathrm{L}+3>$ \\
\hline & 176.0 & 0.3337 & $0.40|\mathrm{H}-2 \rightarrow \mathrm{L}+3>-0.35| \mathrm{H}-3 \rightarrow \mathrm{L}+3>$ \\
\hline \multirow[t]{7}{*}{ (V) } & 307.2 & 0.9858 & $0.65 \mid \mathrm{H} \rightarrow \mathrm{L}>$ \\
\hline & 208.6 & 0.1249 & $0.40|\mathrm{H} \rightarrow \mathrm{L}+4>0.31| \mathrm{H}-1 \rightarrow \mathrm{L}+3>$ \\
\hline & 205.2 & 0.7108 & $-0.42|\mathrm{H} \rightarrow \mathrm{L}+1>0.41| \mathrm{H}-3 \rightarrow \mathrm{L}>$ \\
\hline & 188.7 & 1.7739 & $-0.42|\mathrm{H}-3 \rightarrow \mathrm{L}+1>0.40| \mathrm{H}-4 \rightarrow \mathrm{L}+2>$ \\
\hline & 184.4 & 0.6474 & $0.52|\mathrm{H}-1 \rightarrow \mathrm{L}+2>0.32| \mathrm{H}-3 \rightarrow \mathrm{L}>$ \\
\hline & 179.3 & 0.3371 & $0.39|\mathrm{H} \rightarrow \mathrm{L}+4>-0.35| \mathrm{H}-1 \rightarrow \mathrm{L}+3>0.38 \mid \mathrm{H}-5 \rightarrow \mathrm{L}>$ \\
\hline & 131.5 & 0.4564 & $-0.50 \mid \mathrm{H}-1 \rightarrow \mathrm{L}+8>$ \\
\hline \multirow[t]{4}{*}{ (VI) } & 298.3 & 0.7773 & $-0.64 \mid \mathrm{H} \rightarrow \mathrm{L}>$ \\
\hline & 202.6 & 0.8699 & $-0.42|\mathrm{H} \rightarrow \mathrm{L}+1>0.43| \mathrm{H}-2 \rightarrow \mathrm{L}>$ \\
\hline & 186.2 & 1.8645 & $0.32|\mathrm{H}-1 \rightarrow \mathrm{L}+5>-0.46| \mathrm{H}-2 \rightarrow \mathrm{L}+1>$ \\
\hline & 164.6 & 0.4742 & $-0.57 \mid \mathrm{H}-4 \rightarrow \mathrm{L}+1>$ \\
\hline \multirow[t]{5}{*}{ (VII) } & 293.4 & 0.7483 & $0.64 \mid \mathrm{H} \rightarrow \mathrm{L}>$ \\
\hline & 200.9 & 0.9019 & $0.56|\mathrm{H} \rightarrow \mathrm{L}+2>-0.38| \mathrm{H}-1 \mathrm{v} \rightarrow \mathrm{L}>$ \\
\hline & 185.2 & 2.0596 & $-0.36|\mathrm{H} \rightarrow \mathrm{L}+5>0.35| \mathrm{H}-3 \rightarrow \mathrm{L}+4>$ \\
\hline & 157.5 & 0.5660 & $-0.52 \mid \mathrm{H}-6 \rightarrow \mathrm{L}+3>$ \\
\hline & 142.7 & 0.3470 & $0.55|\mathrm{H}-4 \rightarrow \mathrm{L}+6>-0.37| \mathrm{H}-5 \rightarrow \mathrm{L}+8>$ \\
\hline \multirow[t]{6}{*}{ (VIII) } & 332.8 & 0.4892 & $0.57|\mathrm{H} \rightarrow \mathrm{L}>-0.34| \mathrm{H}-1 \rightarrow \mathrm{L}+4>$ \\
\hline & 227.6 & 1.4616 & $0.34|\mathrm{H} \rightarrow \mathrm{L}>0.37| \mathrm{H}-1 \rightarrow \mathrm{L}+4>$ \\
\hline & 202.5 & 0.5479 & $0.43|\mathrm{H} \rightarrow \mathrm{L}+2>0.35| \mathrm{H}-1 \rightarrow \mathrm{L}+6>0.32 \mid \mathrm{H}-3 \rightarrow \mathrm{L}>$ \\
\hline & 194.6 & 1.7599 & $-0.46|\mathrm{H}-3 \rightarrow \mathrm{L}+2>-0.46| \mathrm{H}-4 \rightarrow \mathrm{L}+3>$ \\
\hline & 181.4 & 0.4193 & $-0.46|\mathrm{H} \rightarrow \mathrm{L}+5>0.43| \mathrm{H}-5 \rightarrow \mathrm{L}>$ \\
\hline & 168.4 & 0.7029 & $-0.34|\mathrm{H}-2 \rightarrow \mathrm{L}+3>0.44| \mathrm{H}-4 \rightarrow \mathrm{L}+1>$ \\
\hline
\end{tabular}


Theoretical absorption spectra (TAS) for all alkynes investigated in this work are shown in Fig. 3 for comparison. The simulations were performed using the ZINDO program. These spectra were obtained by describing each of the principal transitions using a suitably weighted Gaussian function normalised to the calculated oscillator strengths and the curves

Table 3. Dipole moment (in Debye) for neutral and excited (singlet and triplet) states of the alkynes presented in Table 1. (G.S., S.E.S. and T.E.S correspond to ground, singlet excited and triplet excited states, respectively).

\begin{tabular}{cccc}
\hline Molecule & G.S. & S.E.S. & T.E.S. \\
\hline I & 0.00 & 0.00 & 0.00 \\
II & 1.45 & 2.46 & 12.40 \\
III & 0.00 & 0.00 & 0.00 \\
IV & 6.99 & 8.65 & 20.37 \\
V & 0.00 & 0.00 & 0.00 \\
VI & 2.47 & 2.84 & 5.94 \\
VII & 0.00 & 0.00 & 0.00 \\
VIII & 0.00 & 0.00 & 0.00 \\
\hline
\end{tabular}

presented were obtained from gaussian functions weighted (and normalized) by the oscillator strengths (o.s.). The geometry obtained shows a backbone conformation and the most stable structures were found to be essentially planar.

The presence of the $p-\mathrm{NH}_{2}$ (II) results in a very similar behavior on TAS. However two $\mathrm{NO}_{2}$ groups (III) lead to $\mathrm{a} \approx 40 \mathrm{~nm}$ red shift in the main band and all bands composed by HOMO to LUMO $(\mid \mathrm{H} \rightarrow \mathrm{L}>)$ transition. For alkyne IV (Fig. 2(IV) and Table 2(IV)) a red $60 \mathrm{~nm}$ shift in the $\mathrm{H} \rightarrow \mathrm{L}>$ by the inclusion of composition $\mathrm{NO}_{2}$ and $\mathrm{OCH}_{3}$. Two $\mathrm{OCH}_{3}$ groups (V) represent almost the same original band of alkyne without pair donor-acceptor. The inclusions of Nitrogen atom in the phenyl ring (VII and VIII) don't change the composition and position of the first absorption band. Another case is the alkyne with 2 triple bonds between phenyl rings (VIII). In this case it is possible follow two propositions: (a) a red shift in the first $\mid \mathrm{H} \rightarrow \mathrm{L}>$ transition and (b) the inclusion of deep transitions as principal transitions, e.g., $\mid \mathrm{H}-1 \rightarrow \mathrm{L}+6>$ transition for VIII and in the same region for $\mathrm{I}$ is $\mid \mathrm{H} \rightarrow \mathrm{L}+1>$ at region of $200 \mathrm{~nm}$. Details of the transitions are presented in Table 2.

We have carried out the DNdM-INDO/S-CI calculations to simulate the emission (fluorescence and phosphores-

Table 4. Bond Length (Angstrons) of the alkynes molecules described by Table 1 .

\begin{tabular}{l|ccccccc}
\hline Atom Number & \multicolumn{7}{|c}{ Bond length (Angstron) } \\
\hline & I & II & III & IV & V & VI & VII \\
$2-1$ & 1.389 & 1.389 & 1.388 & 1.387 & 1.389 & 1.389 & 1.394 \\
$3-2$ & 1.391 & 1.391 & 1.400 & 1.400 & 1.398 & 1.391 & 1.353 \\
$4-3$ & 1.391 & 1.391 & 1.400 & 1.400 & 1.405 & 1.391 & 1.352 \\
$5-4$ & 1.389 & 1.389 & 1.388 & 1.387 & 1.385 & 1.389 & 1.394 \\
$6-5$ & 1.399 & 1.399 & 1.399 & 1.400 & 1.397 & 1.399 & 1.399 \\
$7-6$ & 1.415 & 1.414 & 1.415 & 1.413 & 1.414 & 1.415 & 1.414 \\
$8-7$ & 1.195 & 1.195 & 1.195 & 1.195 & 1.195 & 1.195 & 1.194 \\
$9-8$ & 1.415 & 1.414 & 1.415 & 1.413 & 1.414 & 1.414 & 1.414 \\
$10-9$ & 1.399 & 1.399 & 1.399 & 1.401 & 1.401 & 1.399 & 1.399 \\
$11-10$ & 1.389 & 1.386 & 1.388 & 1.384 & 1.385 & 1.394 & 1.394 \\
$12-11$ & 1.391 & 1.402 & 1.400 & 1.405 & 1.405 & 1.353 & 1.353 \\
$13-12$ & 1.391 & 1.403 & 1.400 & 1.399 & 1.398 & 1.353 & 1.352 \\
$14-13$ & 1.389 & 1.386 & 1.388 & 1.389 & 1.390 & 1.394 & 1.394 \\
& & & & & & & - \\
$15-12$ & - & 1.428 & 1.498 & 1.378 & 1.380 & - & - \\
$16-15$ & - & - & 1.214 & 1.406 & 1.406 & - & - \\
$17-15$ & - & - & 1.214 & - & - & - & - \\
$18-3$ & - & - & 1.498 & - & - & - & - \\
$19-18$ & - & - & 1.214 & - & - & - & - \\
$20-18$ & - & - & 1.214 & - & - & - & - \\
$17-3$ & - & - & - & 1.495 & 1.380 & - & - \\
$18-17$ & - & - & - & 1.215 & 1.406 & - & - \\
$19-17$ & - & - & - & 1.215 & - & - & - \\
\hline
\end{tabular}

Typical H-X bond $=1.095 \pm 0.05 ; \mathrm{X}=\mathrm{C}, \mathrm{O}, \mathrm{N}$. 
Table 5. Bond Length (Angstrons) of the alkyne VIII described by Table 1.

\begin{tabular}{cc}
\hline Atom Number & Bond length(Angstron) \\
\hline & VIII \\
$2-1$ & 1.389 \\
$3-2$ & 1.391 \\
$4-3$ & 1.391 \\
$5-4$ & 1.389 \\
$6-5$ & 1.399 \\
$7-6$ & 1.414 \\
$8-7$ & 1.196 \\
$9-8$ & 1.365 \\
$10-9$ & 1.196 \\
$11-10$ & 1.414 \\
$12-11$ & 1.399 \\
$13-12$ & 1.389 \\
$14-13$ & 1.391 \\
$15-14$ & 1.391 \\
$16-15$ & 1.389 \\
\hline
\end{tabular}

Typical H-C bond $=1.095 \pm 0.001$

cence) spectra (theoretical emission spectra (=TES)) of alkynes. We follow the same TAS procedure and these spectra were obtained by broadening each of these principal transitions by a suitably weighted gaussian function normalized to the calculated oscillator strengths and the results are showed in Fig. 4 and Fig. 5. In all cases a significant Stokes shift is predicted. This scale effect (red shift for TES compared with TAS) was found mainly because the charge rearrangements of the molecules in the excited states.

Table III presents the dipole moment values of the molecules studied. The unusually large values, predicted for the triplet excited state dipoles of molecules II and IV can be understood in terms of the conformation differences for these alkynes. Note that for the ground state, the backbone geometries of these molecules presented only small modifications and it is shown in Tables 4 and 5.

\section{Summary}

Design of new materials is important to understand their physical and electronic properties and the alkynes molecules belong to this category. In this contribution, we have employed a quantum chemistry methodology (DNdM-INDO/S-CI, INDO/S-CI and PM3-CI) to simulate the ground and the first excited states (singlet and triplet) of a series substituted diphenylacetylene molecules (I-VII) and a dyine (VIII). The last alkyne studied (VIII) gives us some insight of behavior of the inclusion different number of triple bonds between the phenyl rings and a more complete investigation in this direct is in progress. The results presented show us the possibility of improve the properties of alkynes by chemical modifications that combine: (a) increase in the unsaturation and (b) modification of the acceptor/ donor properties of the susbtituents.

\section{Acknowledgments}

We thank the Brazilian agencies FAPESP, CAPES and $\mathrm{CNPq}$ for financial support.

\section{References}

1. Rosseto, R.; Vargas, M.D.; Del Nero, J. International Journal of Quantum Chemistry, accepted.

2. Bunz, U.H.F. Chem. Rev. v. 100, p. 1605, 2000.

3. Rosseto, R. Ph.D. Thesis, Universidade Estadual de Campinas, São Paulo, Brazil, 2002.

4. Stang, P.J.; Diederich, F. Modern Acetylene Chemistry, eds, Weinheim, 1995.

5. Bunz, U.H.F.; Enkelmann, V.; Rader, J. Organometallics, v. 12 , p. $4745,1993$.

6. Wiegelmann, J.E.C.; Bunz, U.H.F. Organometallics, v. 12 , p. $3792,1993$.

7. Jia, G.; Puddephatt, R.J.; Vittal, J.J.; Payne, N.C. Organometallics, v. 12, p. 263, 1993.

8. Bunel, E.E; Valle, L.; Jones, N.L.; Carroll, P.J.; Ganzalez, M.; Munoz, N.; Manriquez, J.M. Organometallics, v. 7, p. 789,1988 .

9. Whittall, I.R.; McDonagh, A.M.; Humphrey, M.G.; Samoc, M. Adv. Organomet. Chem., v. 43, p. 349, 1999.

10. Sonogashira, K.; Tohda, Y.; Hagihara, N. Tetrahedron Lett., v. 16, p. 4467, 1975.

11. Yang, C.; Nolan, S.P. Organometallics, v. 21, p. 1020, 2002.

12. Torres, J.C.; Pilli, R.A.; Vargas, M.D.; Violante, F.A.; Garden, S.J.; Pinto, A.C. Tetrahedron, v. 58, p. 4487, 2002.

13. Brandsma, L. Preparative Acetylene Chemistry, Elsevier Publishing Co., Amersterdam, 1971.

14. Dewar, M.J.S.; Thiel, W. J. Am. Chem. Soc., v. 99, p. 4899, 1977.

15. Stewart, J.J.P. MOPAC Program Version 6 (QCEP 455).

16. Head, J.D.; Zerner, M.C. Chem. Phys. Lett., v. 122, p. $264,1985$.

17. Head, J.D.; Zerner, M.C. Chem. Phys. Lett., v. 131, p. $359,1986$.

18. Anderson, W.P.; Edwards, W.D.; Zerner, M.C. Inorg. Chem., v. 25, p. 2728, 1986.

19. Edwards, W.D.; Zerner, M.C. Theoret. Chim. Acta, v. 72 , p. $347,1987$.

20. Del Nero, J.; Laks, B. Synth. Met., v. 101, p. 440, 1999.

21. Del Nero, J.; Laks, B. Synth. Met., v. 101, p. 379, 1999.

22. Doretto, R.L.; Del Nero, J.; Laks, B. Synth. Met., v. 101, p. 178, 1999.

23. Del Nero, J.; de Melo, C.P. Synth. Met., v. 121, p. 1741, 2001. 